
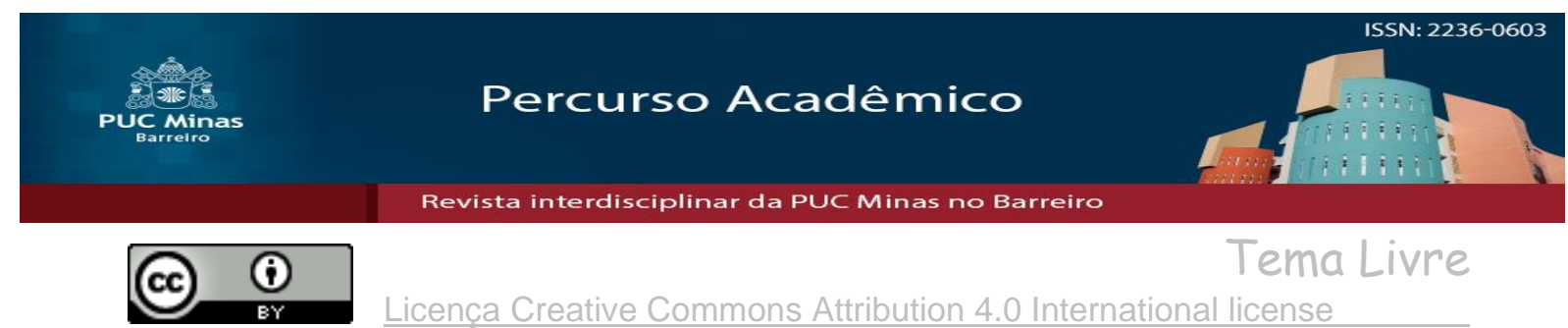

\title{
A aplicação do direito de arrependimento nas aquisições por meio digital no estabelecimento comercial
}

\section{The application of the repentance right in digital means acquisitions in commercial establishment}

\author{
Ana Paula Marques Andrade ${ }^{1}$ \\ Maria Lúcia Veiga Torres ${ }^{2}$
}

\begin{abstract}
RESUMO
O trabalho objetiva investigar e refletir criticamente sobre os aspectos relevantes na aplicação do direito de arrependimento nas aquisições por meios digitais e outros equiparados, realizadas no estabelecimento comercial quando o consumidor não tem acesso ao produto. O Código de Defesa do Consumidor (CDC) prevê o direito de arrependimento para as compras realizadas fora do estabelecimento comercial com a finalidade de proteger a vulnerabilidade do consumidor diante de abordagens de práticas de vendas incisivas, sem reflexão e discernimento suficiente para contratar, que não houve condições de avaliação pelo consumidor sobre o bem contratado. Ocorre que em compras realizadas dentro do estabelecimento comercial, mas sem que o consumidor tenha acesso ao produto, esse direito de arrependimento não poderá ser exercido. Nessa perspectiva, a pesquisa analisa a evolução do direito do consumidor no mundo e no Brasil, os princípios mais relevantes que orientam a proteção do consumidor no CDC, o direito de arrependimento, seus fundamentos e requisitos necessários para seu exercício. Conclui-se, que diante dos princípios estudados, a aplicação do direito de arrependimento deve incidir sobre as compras em que o consumidor não teve acesso ao produto, mesmo que tenham sidas realizadas no estabelecimento da empresa. Para esse resultado, o estudo utilizou o método dedutivo, por meio de pesquisa exploratória, consultando fontes bibliográficas e documentais, estas consistentes na análise de jurisprudência, legislação e projetos de lei.
\end{abstract}

Palavras-chave: Proteção do Consumidor; Direito de Arrependimento; Meios Digitais.

\begin{abstract}
The work aims to investigate and critically reflects about the relevant aspects in the enforcement of the right of repentance in acquisitions by digital and other means, carried out in the commercial establishment, when the consumer does not have access to the product. The Consumer Defense Code (CDC) provides for the right of repentance for purchases made outside the commercial establishment, in order to protect the consumer vulnerability, in the face of incisive sales practices approaches, without enough reflection and discernment to contract or not that, with much less evaluation conditions on the goods hired. For this reason, the research problem comes up, since there is no prevision in the CDC so that this right is applied to purchases where, despite having been carried out inside the commercial establishment, and the consumer did not have access to the product. From this perspective, the research analyzes, the evolution of the right of repentance in the world and in Brazil, the main principles that guide the consumer protection in the CDC, the right of repentance, its foundations and the necessary requirements for its exercise. It may therefore be concluded that, in face of the principles studied, the enforcement of the right of repentance should affect
\end{abstract}

Artigo recebido em 23 de agosto de 2021 e aprovado em 29 de setembro de 2021.

${ }^{1}$ Mestra pela Universidade Federal do Mato Grosso (UFMT), especialista em Direito e Processo do Trabalho e Direito Previdenciário pela Escola Superior do Ministério Público de Mato Grosso, Membro do Grupo de Pesquisa "O meio ambiente do trabalho equilibrado como componente do trabalho decente" (GPMAT/PPGD/UFMT) Atualment, Servidora pública do Poder Judiciário do Estado de Mato Grosso, Brasil. E-mail: paula.ana@unemat.br

2 Licenciada em Pedagogia pela Faculdades Integradas de Diamantino e Bacharel em Direito pela (UFMT), Brasil. E-mail: vtpapel@hotmail.com 
purchases, even if made inside the company's establishment, and the consumer did not have access to the product. For this result, the study used the deductive method, appropriating exploratory research, by means of bibliographic and documentary sources, it is consistent in the analysis of case law, legislation and bills.

Keywords: Consumer Protection; Right of Repentance; Digital Media.

\section{INTRODUÇÃO}

A entrada em vigor da Lei n. 8.078/1990, o CDC, foi uma grande conquista para os consumidores, por ter como objetivo primordial protegê-los, por serem estes a parte mais vulnerável na relação de consumo. Um dos direitos que se destaca para efetivar essa proteção é o direito de arrependimento, o qual é aplicado quando a compra é realizada fora do estabelecimento da empresa, tendo como finalidade proteger a vulnerabilidade do consumidor, diante de abordagens de práticas de vendas incisivas, sem reflexão e discernimento suficiente para contratar ou não, com bem menos condições de avaliação sobre o bem contratado.

O grande avanço da tecnologia no final do século XX, desencadeou evoluções e transformações nas relações comerciais, de forma global, especialmente pelo crescimento da utilização da internet. Evoluções essas, que têm reflexo direto nas relações econômicas e sociais, que alteraram suas formas e meios de realizar as contratações entre consumidor e fornecedor, surgindo assim novas demandas e litígios, que exigem do Direito soluções para harmonizar esses conflitos.

Com isso, a questão que norteou a pesquisa partiu da premissa sobre a possibilidade de aplicação do direito de arrependimento nos casos em que a aquisição é realizada no estabelecimento, porém o produto/serviço só é apresentado ao consumidor por meios digitais, como computador, tablet, folders, catálogos, sem que o produto seja apresentado ao consumidor no momento da aquisição, de maneira que se questiona: Seria possível a aplicação do direito de arrependimento também em tais situações?

Para tanto, o trabalho é dividido em três seções, a primeira seção retrata o surgimento do direito do consumidor no mundo e no Brasil. Em seguida, o estudo pontua a proteção do consumidor no $\mathrm{CDC}$, tratando especificamente dos princípios mais relevantes nas relações de consumo, e por fim, a última seção trata do direito de arrependimento, enfatizando os seus requisitos e fundamentos para o seu exercício, e ainda apresenta as razões para a sua aplicação às compras realizadas no estabelecimento, mas sem que o consumidor tenta tido contato com o produto adquirido, tal como acontece quando uma compra é realizada pela internet. Foi analisado o entendimento jurisprudencial dos Tribunais, em relação a esse tema, bem como apresentado o Projeto 
de Lei (PL) n. 3.514/2015 e suas propostas de alterações ao artigo 49 do CDC que vão ao encontro do que se defende neste trabalho.

A pesquisa é de abordagem de investigação e reflexão crítica do direito de arrependimento, por não serem raros os casos em que o consumidor é atendido no estabelecimento do fornecedor, no modo presencial, mas sem nenhum contato físico com o produto/serviço, ocasião em que a apresentação do produto é apenas por meios digitais, em razão de não estar disponível no mostruário físico da empresa.

O trabalho utilizou do método dedutivo de pesquisa teórica e estudo a respeito da aplicação do direito de arrependimento nas relações de consumo, cuja fonte de pesquisa é a bibliográfica, e ainda, a fonte documental, por meio de estudo e análise de normas jurídicas sobre o assunto, como a Constituição da República Federativa do Brasil (CRFB) e o CDC, jurisprudência dos Tribunais de Justiça e ainda projetos de leis. O estudo da jurisprudência deu-se utilizando palavras-chaves relacionadas ao tema com os seguintes termos de busca "direito de arrependimento; art. 49 CDC", "direito de arrependimento; na loja física", "direito de arrependimento; sem acesso ao produto", nos Tribunais de Justiça dos Estados de São Paulo, Rio Grande do Sul e Mato Grosso, com isso, foram encontradas decisões judiciais nos Tribunais de Justiça do Estado de São Paulo e do Estado do Rio Grande do Sul, apenas.

\section{DIREITO DO CONSUMIDOR NA ERA DIGITAL}

A população mundial vem sendo submetida ao expressivo avanço da tecnologia, que impacta de forma acentuada as relações jurídicas, em diversos setores: econômico, político e social. Diante desta conjuntura, as relações de consumo, sobretudo no meio digital, sofrem alterações estruturais e comportamentais, tanto pelo consumidor como pelo fornecedor. Essas mudanças exigem do direito, adequação e acompanhamento, pois tais relações apresentam demandas e muitos conflitos, em razão de serem muito dinâmicas e velozes, bem como por estar a sociedade em constante evolução.

Nesse sentido, Bolina (2018, p. 13) diz que desde o surgimento da sociedade, o comércio sempre esteve presente, como intermediário nos negócios, criando novos caminhos, encurtando distâncias e aproximando civilizações. No século XX, o comércio sofreu uma revolução inovadora com a internet, facilitando a comunicação entre pessoas de diferentes e distantes lugares do mundo, de maneira que os meios digitais se fizeram cada vez mais presentes na vida das pessoas, inclusive nas relações de consumo com o propósito de facilitar as negociações. 
Com isso, nos tópicos a seguir, será analisada a evolução do direito do consumidor no mundo e no Brasil até os dias atuais, considerando a proteção do consumidor quando uma relação de consumo é intermediada por meios digitais.

\subsection{Evolução do direito do consumidor no mundo}

O desenvolvimento dos direitos do consumidor no mundo finda por confundir com o próprio desenvolvimento das sociedades, por ser marcado pelas principais transformações históricas que trazem influências e reconhecimento nos mais diversos pontos do globo.

Doutrinariamente, não existe consenso a respeito do marco inicial do surgimento do direito do consumidor no mundo. Contudo, é possível detectar o seu início nos países nórdicos. Com o final de duas guerras mundiais e o reconhecimento dos direitos de terceira dimensão, diga-se, os direitos sociais, mesmo que formalmente, conforme a literatura, começam a surgir as positivações e reconhecimento de tais direitos, dentre eles, o direito do consumidor.

Inicialmente, os direitos dos consumidores registram regras que, mesmo sendo muito rudimentares, já eram dotadas de natureza de proteção ao consumidor, como "o decreto do Rei Luís IX, na França em 1481, que determinava que aqueles que vendessem manteiga com pedra dentro, ou colocassem água no leite, seriam punidos com banho escaldante" (INFANTE, 2008, p.11). Esse tipo de atitude mesmo em séculos passados, demonstram que de certa forma já existiam punições para o comerciante que tentava ludibriar os seus clientes.

No contexto capitalista, embora a Revolução Industrial tenha marcado a história das sociedades, foi a última guerra mundial que possibilitou um grande avanço no consumo, trazendo reflexos a partir da segunda metade do século XX no mundo todo. São substancialmente alterados os meios de produção que passam a ser em série e de massa, colocando à disposição do consumidor uma diversidade infinita de produtos.

A concorrência entre os comerciantes levou a inovações de técnicas de vendas mais agressivas e persuasivas com o fim de atrair o consumidor, que passa a ocupar uma posição principal na relação de consumo. Dessa maneira, o compromisso do produtor de informar não evoluiu na mesma proporção, em razão da busca por lucros sem preocupação com a qualidade e segurança dos produtos, necessitando a intervenção do Estado com a positivação de direitos para a regulação destas relações.

Foi no século XX ainda, que em vários países já haviam alguns movimentos e 
legislações que visavam proteger o consumidor. Historicamente, um dos marcos principais da preocupação com os direitos do consumidor, deu-se nos Estados Unidos da América (EUA), em 15 de março de 1.962, por ocasião da mensagem que o Presidente John Kennedy enviou ao Congresso, que dizia:

\begin{abstract}
Consumidores, por definição, somos todos nós. Os consumidores são o maior grupo econômico na economia, afetando e sendo afetado por quase todas as decisões econômicas, públicas e privadas [...]. Mas são o único grupo importante da economia não eficazmente organizado e cujos posicionamentos quase nunca são ouvidos (KENNEDY, 1962, MENDONÇA, apud CAVALIERI FILHO, 2014, p. 5).
\end{abstract}

$\mathrm{Na}$ opinião do presidente John Kenneddy, sem assegurar os direitos do consumidor, "o mundo colocava em risco a economia capitalista" (SAIKI, 2012, p. 116). Portanto, pode-se dizer que o Direito do Consumidor teve seu real início nos EUA, pois o próprio presidente do país na época, se preocupou com os direitos dos consumidores, já que se auto declarava também como um consumidor. Desde então, a data de 15 de março passou a ser considerada pela Organização das Nações Unidas (ONU) como o Dia Mundial dos Direitos dos Consumidores. E no Brasil, por meio da Lei n ${ }^{\circ} 10.504 / 2002$, de 8 de julho de 2002, foi instituído o Dia Nacional do Consumidor, que também será comemorado, anualmente, no dia 15 de março.

A contribuição principal para os avanços dos direitos do consumidor em âmbito mundial advém do empenho da ONU que passou a orientar e sugerir legislações mais rígidas de proteção ao consumidor, despertando nos países a consciência da necessidade protetiva. Como marco efetivo dessa orientação e aplicação dos direitos de terceira dimensão, sociais, citam-se como pontos centrais o direito consumerista e o princípio da dignidade da pessoa humana, delineados na Resolução da ONU n 39/248, de normas diretivas.

A partir desse momento, países como Noruega, França, Suécia, Alemanha e Dinamarca passaram então, a seguir as recomendações da ONU e a criarem leis específicas de proteção aos consumidores, ou mesmo extravagantes, como no caso do Brasil, com a elaboração de um código protetivo (INFANTE, 2008, p. 19), cujo estudo da evolução desse direito será aprofundado no próximo item.

\title{
2.2 Evolução do direito do consumidor no Brasil
}

As relações de consumo entre os indivíduos iniciaram antes mesmo da era do 
cristianismo no mundo, visto que, as primeiras relações comerciais eram realizadas por meio do escambo, de alimentos, geralmente por produtos que precisavam e eram tragos por viajantes, nômades entre outros (SILVA NETO, 2013, p. 4).

Desse modo, não haviam regras que protegessem exclusivamente as relações de consumo no Brasil Colônia e no Império. O que acontecia era apenas a regulamentação das relações de mercado e consumo com uma leve proteção ao consumidor. Foi a partir da Independência do Brasil que surgiram outros meios de regulamentação das relações de consumo, como o Código Comercial, que trouxe normas como a nulidade de contratos comerciais, interpretação e também o dever de qualidade entre outros (SILVA NETO, 2013, p. 4), de maneira que tal código, além de coibir práticas desleais, incentivava o cumprimento conforme acordo firmado no contrato, bem como exigia a qualidade dos produtos e serviços que eram comercializados.

Assim, é possível perceber que naquela época, por mais que as relações de consumo ainda fossem poucas e/ou simples, já havia a preocupação com os contratos comerciais e com a possibilidade deles serem cancelados por algum motivo. Com efeito, segundo Silva Neto (2013, p. 4), no Código Civil Brasileiro de 1916, que foi regulamentado as transações de mercado, assim como na Lei sobre Responsabilidade Civil no Transporte Ferroviário de 1912 e na Lei da Usura de 1933, encontraram-se normas de proteção comerciais. Independente da época, o que se verifica é que o direito do consumidor foi se estabelecendo entre os fornecedores brasileiros.

Portanto, o direito do consumidor nasceu para o Direito a partir da metade do século XX, sendo considerado um novo ramo jurídico, tanto na doutrina como na legislação, com a função de equilibrar os arrolamentos contratados entre fornecedores e consumidores. Esse fato se deu na verdade devido ao surgimento do Movimento Consumerista, que apresentou a realidade quanto a posição dos consumidores que deixaram de ser vistos como os reis do sistema para se tornarem vítimas e ou servos desse sistema (SILVA, 1990, p. 70). Com isso, surgiu a necessidade da intervenção do Estado nas relações de consumo.

Pode-se dizer então, que a tomada de medidas de proteção ao consumidor aconteceu de maneira gradativa não só nos outros países, mas também no Brasil, tendo em vista a abertura entre a organização dos grupos, a conscientização da sociedade e a pressão exercida sobre os poderes político e legislativo.

O Estado de São Paulo foi um dos precursores na adoção de legislações de 
proteção do consumidor, por meio da edição do Decreto $n^{\circ} 7.890$, de 1976, o qual era restrito à esfera estadual (INFANTE, 2005, p. 22).

Assim com o passar do tempo, foram surgindo outras leis federais que criavam direitos para os consumidores, sendo criados importantes órgãos protetivos conhecidos como Procon (Programa de Proteção de Defesa do Consumidor) em 1976, Idec (Instituto de Defesa do Consumidor) em 1987, CNDC (Conselho Nacional de Defesa do Consumidor) em 1985 que foi extinto em 1990, e recriado por meio do Decreto governamental no 10.417/2020, e o Inmetro (Instituto Nacional de Metrologia, Qualidade e Tecnologia), em 1.973, que acabou formando uma rede de proteção ao consumidor e ao fornecedor também (INFANTE, 2008, p.22).

Portanto, verifica-se que a necessidade de proteção ao consumidor surgiu com muita força nos anos 1950, com um grande crescimento na década de 70, tendo o seu ápice nos anos 80 e 90. Toda essa transformação não aconteceu somente pela vontade da sociedade, mas sim pelas reivindicações de alguns doutrinadores e legisladores da época, e principalmente pelo grande impulso na efetivação dos direitos sociais, com entrada em vigor da CRFB em 1988, intitulada por Ulisses Guimarães como a Constituição Cidadã, bem como o art. 48 do Ato das Disposições Constitucionais e Transitórias (ADCT), o qual estipulou um prazo de 120 dias para que fosse elaborado o CDC pelo legislativo.

Desse modo, em 11 de setembro de 1.990, entra em vigor o Código Brasileiro de Defesa do Consumidor, com a promulgação da Lei 8.078/90.

\subsection{O uso de meios digitais nas relações de consumo presenciais e a proteção do consumidor}

A tecnologia provocou uma série de transformações nas relações humanas, já que facilitou a comunicação e o acesso a muitas informações por meio digital. Diante dessa novidade, o sistema de compra e venda também passa constantemente por inovações, se adequando à realidade dos novos consumidores.

Nesse sentido, surgiu o comércio eletrônico facilitando a realização de pesquisas por produtos, serviços, valores entre outros, que hoje são comercializados via internet em páginas virtuais, promovendo maior agilidade no processo de compra e venda, tanto dentro da mesma cidade como até em outros estados e/ou países. Desse modo, em relação ao comércio eletrônico, Lima (2008, p. 59) o define:

Como relações negociais que são realizadas por meio de computadores, onde as transações comerciais são realizadas eletronicamente, com o objetivo de 
melhorar a eficiência e a efetividade do mercado e dos processos comerciais, entende-se assim, que esta modalidade de compra e venda de produtos e serviços, que são oferecidos para os clientes dessa maneira, fez com que a presença do consumidor deixe de ser essencial, visto que este ato pode ser firmado à distância.

Com o comércio eletrônico cada vez mais em evidência, aumentaram as preocupações em relação a proteção do consumidor nessa nova modalidade de transação, eis que aqui é patente que o consumidor se encontra numa vulnerabilidade maior, pois não tem acesso direto ao produto, e por isso, o CDC prevê o direito de arrependimento a ser exercido pelo consumidor.

Em muitas ocasiões, o comércio com atendimento presencial acaba utilizando de meios digitais (computador, tablet etc.) para a realização de suas vendas, de modo que surge a necessidade de identificar e estudar como são protegidas as relações de consumo nos casos em que o consumidor realiza a aquisição de um determinado produto no estabelecimento da empresa, sendo que esse produto foi apresentado a ele apenas por meios digitais, sem nenhum contato físico. Em situação semelhante, isto é, quando o consumidor adquire o produto fora do estabelecimento comercial, ele pode exercer o direito ao arrependimento por não ter tido acesso ao produto anteriormente.

Ganha relevância, portanto, investigar como as normas do CDC podem propiciar segurança e proteção nessas relações de consumo intermediadas por meios digitais, pois cada vez mais as empresas utilizam desses meios, como tablets, computadores e catálogos virtuais para realização dos seus negócios, sem oportunizar que o consumidor tenha contato com os produtos antes da compra e venda.

É factível que essa forma de relação de consumo veio para ficar, porém precisa acontecer de maneira segura, tanto para consumidor como para o fornecedor, incumbindo ao Direito do Consumidor, nas relações que utilizarem meios digitais, oportunizar mecanismos e ferramentas que deem efetividade à proteção e segurança jurídica que exigem as relações de consumo.

\section{A PROTEÇÃO DO CONSUMIDOR NO CÓDIGO DE DEFESA DO CONSUMIDOR}

Um dos grandes desafios em tempos de globalização e de constantes mudanças nas formas de contratações implementadas pela evolução tecnológica é o de efetivar a proteção do consumidor. A partir do disposto no art. 48 do ADCT, em 11 de setembro de 1990, foi promulgada a Lei n. 8.078 que instituiu o CDC no ordenamento jurídico 
brasileiro (MENDONÇA, 2019, p.18).

O CDC, enquanto sistema normativo, busca proteger o consumidor procurando suprir a vulnerabilidade e hipossuficiência deste ante o fornecedor. Contudo, a sua aplicação e interpretação deve se dar conforme a proteção advinda do texto constitucional de forma ampla. Sendo a lei consumerista, baseada em princípios gerais, torna-se necessária quando de sua aplicação, ter em mente sua especialidade e limitação em relação a seus sujeitos, pois essa proteção incide apenas nas relações entre consumidor e fornecedor. Assim, por ser a Lei n. 8.078/1990, uma norma principiológica, serão tratados na sequência os princípios mais importantes para assegurar a proteção da parte mais fraca da relação jurídica de consumo, isto é, do consumidor.

\subsection{Princípio da vulnerabilidade e da hipossuficiência do consumidor}

Da análise do art. $4^{\circ}$, inciso I da Lei 8.078/1.990, é incontestável a intenção do legislador em efetivar o princípio basilar constitucional da dignidade da pessoa humana, atendendo às necessidades básicas do consumidor e dotando-o da vulnerabilidade nas diversas relações de consumo (TARTUCE, NEVES, 2018, p. 470). Essa vulnerabilidade é presumida, como condição jurídica, pois a sua posição na relação de consumo é sempre desfavorável, por não possuir paridade de armas, ante as várias revoluções, historicamente sofridas nas relações de consumo.

Visto por essa ótica, a vulnerabilidade do consumidor pode ser entendida como a fragilização do sujeito de direitos, que torna a relação desequilibrada. Ela não deve ser vista apenas como forma de proteção do mais fraco, mas por ser o princípio que conduzirá a atuação do intérprete do direito.

Nas lições de Tartuce e Neves (2018, p. 48), a vulnerabilidade não é o fundamento das regras de proteção, mas o princípio que orienta, a técnica para as aplicar bem, é a noção instrumental que guia e ilumina a aplicação destas normas protetivas e reequilibradoras, à procura do fundamento da igualdade e da justiça equitativa. $O$ princípio da vulnerabilidade tem relevância por ser orientador e pressuposto de todo sistema protetivo do CDC. Esse princípio estabelece também a submissão do consumidor, pois a vulnerabilidade pode ocorrer de várias formas, podendo ser de ordem técnica, econômica ou jurídica.

A vulnerabilidade técnica pode ser interpretada no sentido de que o consumidor não tem o conhecimento técnico específico sobre os produtos e serviços que adquire, podendo ser enganado (MENDONÇA, 2019, p. 22), diante da exposição do consumidor 
aos meios de ofertas, informações e publicidades sedutoras, que são disseminados pelos mais diversos meios de comunicação.

Já a vulnerabilidade econômica estaria evidenciada pelo desequilíbrio entre uma parte e outra dessa relação de consumo. Assim, "a vulnerabilidade econômica se manifesta pelo grande poder econômico do fornecedor, ou em razão da essencialidade do serviço, que acaba impondo sua superioridade com os que com ele contratam" (MOREIRA, 2016, p. 126).

A massificação dos contratos evidencia outra vulnerabilidade do consumidor, a jurídica, em que não há equivalência ou discussões sobre as regras a serem aplicadas às relações (TARTUCE, NEVES, 2018, p. 48). Essa vulnerabilidade relaciona-se com a ausência por parte do consumidor sobre conhecimentos jurídicos específicos. Contudo, nesse caso, mesmo sendo ela presumida, deve ser analisado no caso concreto os requisitos necessários para sua adoção. Há casos que em hipótese alguma ela pode ser declinada (TARTUCE, NEVES, 2018, p. 48).

Importante destacar que não há que confundir a vulnerabilidade do consumidor com a sua hipossuficiência, pois "todo consumidor é sempre vulnerável, característica intrínseca à própria condição de destinatário final do produto ou serviço, mas nem sempre será hipossuficiente" (TARTUCE, NEVES, 2018, p. 49).

O reconhecimento da hipossuficiência exige uma interpretação para além da sua literalidade, pois não está restrita a condição do consumidor ser pobre ou sem recursos. O conceito de hipossuficiência consumerista é mais amplo, devendo ser apreciado pelo aplicador do direito caso a caso, no sentido de reconhecer a disparidade técnica ou informacional diante de uma situação de desconhecimento (TARTUCE, NEVES, 2018, p. 50).

A hipossuficiência pode ser entendida também como sendo mais uma forma de reivindicar benefícios e as garantias do CDC, qual seja, "a possibilidade de pleitear, no campo judicial, a inversão do ônus de provar, conforme estatui o art. $6^{\circ}$, VIII, da Lei 8.078/1990" (TARTUCE, NEVES, 2018, p. 51).

Diante da condição de vulnerabilidade e hipossuficiência do consumidor estabelecidas pelo CDC, tornam-se igualmente importantes para harmonia das relações de consumo, a divulgação de informações sobre os direitos do consumidor, bem como a difusão de seus direitos à transparência e à informação, tratados a seguir. 


\subsection{Do princípio da transparência e o direito à informação}

A transparência é um dos principais princípios do direito do consumidor, estando expresso no caput do art. $4^{\circ}$ do CDC, o qual traz as obrigações do fornecedor para com o consumidor. Para Nunes (2018, p. 122), o princípio da transparência, expresso no caput do art. $4^{\circ}$ do $\mathrm{CDC}$, se traduz na obrigação do fornecedor em dar ao consumidor a oportunidade de conhecer os produtos e serviços que são oferecidos e, gera no contrato a obrigação de propiciar-lhe o conhecimento prévio de seu conteúdo.

O princípio da transparência tem um caráter educacional, no que diz respeito aos direitos e deveres do consumidor e do fornecedor, disciplinados no inciso IV, do art. $4^{\circ}$ como meio para a harmonização das relações. Essa constatação implica na observância da transparência antes, durante e também após as contratações.

No mesmo sentido, são as lições de Marques (2006, p. 594) apontadas por Tartuce e Neves (2018, p. 59), de que a transparência deve ser:

clara e correta sobre o produto a ser vendido, sobre o contrato a ser firmado, significa lealdade e respeito nas relações entre fornecedor e consumidor, mesmo na fase pré-contratual, isto é, na fase negocial dos contratos de consumo.

O direito de ser informado está diretamente relacionado à transparência e sua disciplina está expressa no art. $6^{\circ}$, inciso III do CDC, como direito básico do consumidor. A identificação do fornecedor, a descrição do produto ou serviço e o esclarecimento das condições do negócio são fundamentais e imprescindíveis para garantir a livre e consciente escolha do consumidor (MOREIRA, 2016, p. 131).

Nos contratos celebrados no estabelecimento, mas por meios digitais, esses dois princípios assumem grande relevância, pois a observância de ambos oportuniza ao consumidor ter informações claras e adequadas sobre o produto ou serviço, eis que nessa modalidade de contrato a aquisição do produto é realizada sem a apresentação física do que está sendo adquirido. Assim, nesses casos, surge a necessidade de que esses princípios, enquanto ferramentas protetivas, sejam adotados também em tais contratos, uma vez que nessas situações evidenciam a possibilidade de incidência do instituto do direito de arrependimento do $\mathrm{CDC}$, já que essa relação é equiparada àquela em que o contrato foi realizado fora do estabelecimento comercial.

\subsection{Do princípio da boa-fé objetiva}

O princípio da boa-fé objetiva é um dos princípios nucleares do CDC, que tem o 
condão de dar sustentação e harmonia à diversas situações, em que o intérprete do direito deve encontrar a melhor maneira de dar equilíbrio às relações de consumo, notadamente aquelas desequilibradas.

No CDC, o princípio da boa-fé objetiva está expresso no art. $4^{\circ}$, inciso III, com objetivo de compatibilizar a proteção do consumidor e a necessidade de desenvolvimento econômico e tecnológico, de aparência contraditórios, viabilizando os princípios fundadores da ordem pública do art. 170 da CRFB. Assim, a boa-fé objetiva pode ser definida, grosso modo, como sendo uma regra de conduta, isto é, o dever das partes de agir conforme certos parâmetros de honestidade e lealdade, a fim de se estabelecer o equilíbrio nas relações de consumo (NUNES, 2018, p. 123).

O equilíbrio aqui a ser estabelecido pela boa-fé objetiva está relacionado não ao poder econômico, mas sim ao equilíbrio nas relações de consumo, em que sua complexidade entre direitos e obrigações, exigem análise criteriosa para a efetiva proteção no caso fático. A boa-fé objetiva possibilita assim, o equilíbrio tanto para o consumidor como ao fornecedor. A ausência da boa-fé objetiva, conforme o art. 51, inciso IV do CDC, é inaceitável, tendo como consequência a nulidade de pleno direito de todas as situações que de alguma forma forem incompatíveis com ela.

Portanto, a boa-fé objetiva possibilita o justo equilíbrio das relações e vincula às partes, sendo de importância fundamental no sistema de defesa do consumidor, dela decorrendo vários outros princípios, como o do direito à informação e à transparência, entre outros, todos possuindo reflexos no direito de arrependimento (INFANTE, 2008, p. $68)$.

Com isso, a boa-fé objetiva é um dos princípios nucleares do CDC, cuja função precípua é impor a todos os participantes da relação de consumo uma atuação com honestidade, conduta moral e ética. Inclusive, dada a sua importância, a sua aplicação se faz necessária em todas as relações jurídicas, sendo contemplada em diversos códigos. É o caso do Código Comercial, do Código Civil, os de classes, tal como o Código de Ética e Disciplina da Ordem dos Advogados do Brasil (OAB) que, em seu art. $2^{\circ}$, parágrafo único, inciso II, contempla a boa-fé como um de seus princípios fundamentais e também um dos deveres do advogado.

\section{O DIREITO DE ARREPENDIMENTO NAS RELAÇÕES DE CONSUMO}

Arrepender-se está relacionado ao ato de, após a tomada de determinada decisão, 
ter a faculdade de voltar atrás, rever a decisão tomada, mudar de opinião, mudar de atitude. Fato muito comum de acontecer, pois quem na vida prática nunca se viu diante de situações de tal natureza?

O CDC traz em seu artigo 49 o direito de arrependimento, como mecanismo protetivo do consumidor. O dispositivo legal estabelece que:

o consumidor pode desistir do contrato, no prazo de sete dias a contar de sua assinatura ou do ato de recebimento do produto ou serviço, sempre que a contratação de fornecimento de produtos e serviços ocorrer fora do estabelecimento comercial, especialmente por telefone ou a domicilio.

A norma consumerista, portanto, permite que o consumidor, dentro do prazo legal, reflita a respeito do produto adquirido de forma consciente e adequada, sem precipitações e livre de marketing agressivo, normalmente utilizados nesses tipos de vendas, e com isso tenha assegurado o direito de arrepender-se.

Contudo, o direito de arrependimento, na disposição legislativa atual, só autoriza o seu exercício se a contratação ocorrer fora do estabelecimento comercial, não tendo disposição legal para sua aplicação nas compras realizadas dentro do estabelecimento por meio digital ou outro meio equiparado. Os requisitos para o seu exercício, bem como os fundamentos que o autorizam serão tratados na próxima seção.

\subsection{Requisitos e fundamentos para o exercício do direito de arrependimento}

O direito de arrependimento tem ganhado relevância no direito, especialmente pelas formas de contratar introduzidas pelas novas modalidades de transações comerciais, cujo prazo para o exercício do direito de arrependimento pode ser entendido como período de reflexão que leva a constituição de um direito potestativo.

Visto dessa forma, Tartuce e Neves (2018, p. 322) lecionam que no direito de arrependimento "a reflexão de sete dias, constitui um direito potestativo colocado à disposição do consumidor, contrapondo-se a um estado de sujeição existente contra o fornecedor ou prestador".

Para o exercício desse direito, é necessário que sejam preenchidos os requisitos de sua configuração, consistentes na (i) existência de relação de consumo e (ii) contratação de fornecimento de produto ou serviço fora do estabelecimento comercial do fornecedor (GOMIDE, 2014, p. 137).

O preenchimento desses dois requisitos é essencial para que incida o direito de arrependimento numa determinada relação de consumo. Assim, nem toda aquisição de 
produto ou serviço terá sua aplicação. Ela se restringe as relações de consumo em que o consumidor é o destinatário final e a contratação ocorra fora do estabelecimento do fornecedor.

O prazo para o exercício do direito de arrependimento, conforme o artigo 49, começa a contar da data da assinatura do contrato ou do recebimento do produto. Tem assim, o consumidor duas possibilidades de início da contagem do prazo para exercer ou não o seu direito, buscando justamente dar condições para a adequada avaliação do produto ou serviço adquirido.

$\mathrm{O}$ artigo 49 do $\mathrm{CDC}$ não exige que consumidor justifique os motivos que o levaram a se arrepender-se para exercer o direito de arrependimento. Essa ausência de imposição de limites ao exercício é motivo de críticas por parte de doutrinadores, que entendem que se abre possibilidades de ocorrer abuso de direito por parte de consumidores que agiriam de má-fé.

A proteção que o CDC busca com o direito de arrependimento é limitar as aquisições sem reflexão, emocionais e expostas a marketing agressivo, em que não é dado ao consumidor a oportunidade de ter o contato físico e de conhecer detalhadamente as características técnicas, qualidade e funcionalidades do produto. Aquisições que possivelmente em situações e condições normais e conscientes não seriam realizadas.

Dessa maneira, o direito de arrependimento tem o condão de proporcionar ao consumidor tempo para refletir sobre a aquisição, isto é, ter a convicção de que ela realmente atende sua expectativa ou necessidade, protegendo, portanto, a sua vulnerabilidade. Nesse sentido é que Ezio Guerinoni citado por Gomide diz que "a função do direito de arrependimento é proteger contra a surpresa e atribui ao sujeito a possibilidade de refletir, de ponderar a conveniência do contrato a ser firmado" (GOMIDE, 2014, p. 51 apud GERINONI, 2014, p. 51)

Os fundamentos do direito de arrependimento do CDC no Brasil, estão diretamente relacionados ao princípio maior da CRFB, a dignidade da pessoa humana, que assegura a proteção à sua vulnerabilidade. Evidencia-se, ser a proteção do consumidor, dever do Estado, pelo que dispõe o art. $5^{\circ}$, inciso XXXII, da CRFB, não podendo de forma alguma ser mitigado por ser um direito fundamental.

Diante disso, vislumbra-se que possibilitar e reconhecer a necessidade de aplicação do direito de arrependimento também nas aquisições e compras realizadas dentro do estabelecimento do fornecedor e que ao mesmo tempo tenham sido realizadas 
por meio digital, se traduz na proteção do consumidor que, a depender do caso fático, especialmente naqueles em que o consumidor não teve acesso ao produto/serviço, é fundamental para protegê-lo.

\subsection{Da aplicação do direito de arrependimento às compras realizadas por meio digital no estabelecimento da empresa}

Indubitavelmente, a entrada em vigor do CDC no ordenamento jurídico brasileiro, representou um grande avanço na conquista de direitos por parte do consumidor. Contudo, passados bem mais de 20 anos, diante das transformações e mudanças nas formas de contratar, o uso de novas tecnologias para intermediar as negociações, fazem com que surjam também novas demandas que ainda não se encontram positivadas no ordenamento jurídico.

Há contratações em que o consumidor realiza a aquisição dentro do estabelecimento, porém o produto só lhe é apresentado por meios digitais, como tablet, computador ou catálogos etc., em que não lhe é oportunizado o contato físico com o produto para conhecê-lo e avaliar suas características, levando-o, em muitas situações, a comprar por impulso, ficando ausente, assim, a necessária reflexão.

Essa situação tornou-se corriqueira, em razão de nem sempre os estabelecimentos terem em seus mostruários físicos, aquele produto descrito e solicitado pelo consumidor.

Desse modo, fica patente a necessidade de uma interpretação, por parte dos intérpretes do direito, que proporcione a aplicação do direito de arrependimento também nessas contratações, pois não tendo o consumidor o acesso ao produto para conhecer e avaliar conscientemente o que está adquirindo, ele estaria nas condições que configuram o direito de arrependimento estabelecido pelo CDC para as aquisições realizadas à distância.

Nesse sentido, a $31^{\text {a }}$ Câmara de Direito Privado do Tribunal de Justiça de São Paulo (TJSP), ao julgar o Recurso de Apelação n. ${ }^{\circ}$ 0004688-42.2010.8.26.0038, que discutia a compra e venda de um veículo, manteve a sentença de primeiro grau com o entendimento de que, não obstante a compra tenha sido realizada dentro do estabelecimento comercial, as circunstâncias da aquisição devem ser levada em conta, pois:

$\mathrm{O}$ apelado não teve acesso ao veículo no momento da compra (“... O embargante não chegou a ver o veículo na loja" fls. 75 , in fine), o que lhe assegura o direito de arrependimento previsto na lei consumerista (art. 49), 
equivalendo a hipótese de contratação à distância (SÃO PAULO, 2013a).

Extrai-se que o entendimento jurisprudencial adotado nesse caso, é de que mesmo a compra sendo realizada no estabelecimento, a incidência do direito de arrependimento ocorreu pelo fato do consumidor não ter acesso ao produto, sendo assim equiparada à aquisição à distância, efetivando dessa maneira, a proteção do consumidor.

Esse entendimento de ampliação da aplicação do direito de arrependimento também foi adotado pela $24^{\mathrm{a}}$ Câmara da Seção de Direito Privado do mesmo Tribunal, ao julgar o Recurso de Apelação n. 00173-72.2018.8.26.506. No caso, a consumidora realizou a aquisição de um sofá/colchão apresentado por meio de catálogo, e arrependeuse dentro do prazo legal previsto no art. 49 do CDC, porém, o fornecedor impôs multa para rescindir o contrato. O Órgão Colegiado decidiu pela aplicação do direito de arrependimento do CDC, assegurando o direito da consumidora, ante sua vulnerabilidade na situação fática, visando coibir a prática agressiva e abusiva de venda mesmo com a contratação tendo sido realizada no estabelecimento do fornecedor.

As relações de consumo são disciplinadas pelo CDC e as formas de harmonizar os conflitos delas resultantes devem levar em conta a proteção do consumidor, alicerçada nos princípios fundamentais consumeristas, especialmente, em situações como as ora examinadas. No mesmo entendimento, são as palavras de Cláudia Lima Marques (2008 apud SÃO PAULO, 2008), citadas na decisão proferida no Agravo de Instrumento n. ${ }^{\circ}$ 1.156.260-0/0 pela 26 Câmara de Direito Privado:

\footnotetext{
A jurisprudência brasileira tem considerado que se o fornecedor utilizou destes métodos emocionais de vendas, há direito de arrependimento do consumidor forte no art. 49 do CDC e nulas são as cláusulas contratuais que tendem impedir o exercício deste direto.
}

Evidencia-se, pelas decisões mencionadas, que é possível que ocorra a aplicação do direito de arrependimento para resguardar a vulnerabilidade do consumidor, coibir e também desestimular práticas abusivas nas compras realizadas dentro do estabelecimento por meio digital.

Nos casos acima, o direito de arrependimento foi assegurado. Contudo, como o CDC só autoriza exercer o direito de arrependimento nos casos em que a compra foi realizada fora do estabelecimento comercial, há decisão em sentido contrário daquilo que pregoa os princípios estudados anteriormente.

Assim, a contradição de entendimento pelos Tribunais torna-se evidente na 
decisão proferida no Recurso Inominado n. ${ }^{0} 71006032197$ da Terceira Turma Recursal Cível dos Juizados Especiais Cíveis do Estado do Rio Grande do Sul, em que o consumidor buscava o exercício do direito de arrependimento com o cancelamento do negócio dentro do prazo legal do art. 49 do CDC. Esse caso específico trata de uma compra de moto, em que o consumidor não teve acesso ao produto, pois o fornecedor não tinha o modelo no estoque. A sentença de primeiro grau julgou parcialmente procedentes os pedidos, permitindo o exercício do direito de arrependimento pelo consumidor. Porém, a empresa recorreu da sentença e a Terceira Turma Recursal, no acórdão, por unanimidade, proveu o recurso e julgou improcedente a demanda, sob o argumento de que em razão da compra ter sido realizada no estabelecimento da empresa, seria inaplicável o direito de arrependimento previsto no art. 49 do CDC (RIO GRANDE DO SUL, 2016).

Diante dessas demandas, visando atualizar o $\mathrm{CDC}$, efetivar a proteção do consumidor e propiciar segurança jurídica a essas relações, teve origem no Senado Federal, o PL n. 281/2012 de autoria do Senador José Sarney - PMDB/AP. Esse projeto foi aprovado no Senado e após, foi encaminhado por meio do ofício no 1.609 (SF) para a Câmara do Deputados (casa revisora), em 04 de novembro de 2015, o qual tramita no regime de prioridade, sob o PL n. 3.514/2015, estando apensado ao PL 4906/2001, PL 4678/2016, PL 6533/ 2016 e PL 9754/2018, os quais tratam de propostas de alterações ao CDC.

O PL n. 3.514/2015 traz importantes alterações à Lei n. 8.078/90, ampliando direitos ao consumidor e regulando matérias que ainda não estão disciplinadas por essa lei. A finalidade dessa ampliação é fortalecer e dar segurança jurídica as relações de consumo, disciplinando o comércio eletrônico na seção VII do CDC, com inserção de vários parágrafos e alterando substancialmente os artigos 45 e 49.

O destaque da alteração do artigo 49, que interessa para o trabalho, considerando sua relevância para as formas/meios como são realizadas as relações de consumo na contemporaneidade e o assunto pesquisado, encontram-se especificamente nos parágrafos $2^{\circ}$ e $3^{\circ}$ do referido projeto nos seguintes termos:

$2^{\circ}$ Por contratação a distância entende-se aquela efetivada fora do estabelecimento ou sem a presença física simultânea do consumidor e do fornecedor, especialmente em domicílio, por telefone, por reembolso postal ou por meio eletrônico ou similar.

$3^{\circ}$ Equipara-se à modalidade de contratação prevista no $\S 2^{\circ}$ deste artigo aquela em que, embora realizada no estabelecimento, o consumidor não tenha 
tido a prévia oportunidade de conhecer o produto ou serviço, por não se encontrar em exposição ou pela impossibilidade ou dificuldade de acesso a seu conteúdo (PLS 3.514/2015).

Em sendo aprovado o PL n. 3.514/2015 e sancionado para ter vigência, estar-se á diante de uma grande conquista para os consumidores. A relevância é que o dispositivo estabelece previsão de possibilidade de ampliação de direitos, em que seria possível ao consumidor exercer o direto de arrependimento, equiparando às contratações realizadas dentro do estabelecimento com as realizadas fora, desde que não fosse oportunizado a ele o conhecimento do produto ou do serviço adquirido.

Contudo, o que existe até o momento é a proposta de alteração legislativa em trâmite, que se prolonga por anos. Assim, até que estejam positivadas as alterações na legislação, a solução para esses casos de litígios quanto a aplicação do direito de arrependimento deve ser orientada pelos princípios fundamentais do $\mathrm{CDC}$, vistos anteriormente, bem como pelo que estabelece os artigos $4^{\circ}$ e $5^{\circ}$ da LINDB (Lei de Introdução às Normas do Direito Brasileiro).

Nesse prisma, conforme destaca Ruy Rosado de Aguiar Júnior (2003, p. 20), a boa-fé objetiva é o princípio de lealdade que deve orientar as relações humanas, de sorte que todos devem permitir sejam realizadas as expectativas que os outros têm nas relações mantidas na vida social, razão pela qual o direito de arrependimento deve ser estendido a todas as situações em que o consumidor não teve acesso ao produto/serviço adquirido.

\section{Considerações Finais}

O direito de arrependimento assegurado legalmente pelo CDC, é previsto para as modalidades de aquisições realizadas à distância, isto é, aquelas que aconteceram fora do estabelecimento do fornecedor, tendo por objetivo proteger a parte vulnerável da relação de consumo. Porém, o expressivo crescimento de meios digitais, como ferramenta na intermediação das contratações entre consumidor e fornecedor, provocou mudanças e alterações nas formas de contratar que afetam também as relações de consumo que são realizadas no estabelecimento comercial.

Assim, a questão que norteou o trabalho de pesquisa, funda-se na premissa de aplicar o direito de arrependimento nos casos em que a aquisição é realizada no estabelecimento, porém o produto/serviço só é apresentado ao consumidor por meios digitais, como computador, tablet, folders, catálogos.

Ao fazer um estudo de como a jurisprudência se posiciona sobre o assunto, foram 
encontrados dois julgados do TJSP e um da Terceira Turma Recursal Cível dos Juizados Especiais Cíveis do Estado do Rio Grande do Sul. Da análise dos acórdãos do TJSP evidenciou-se o entendimento que, mesmo que a contratação tenha sido realizada no estabelecimento por meio digital, o direito de arrependimento foi assegurado, por não ter sido oportunizado ao consumidor o acesso ao bem adquirido, equiparando tais contratações às realizadas à distância, protegendo assim, o consumidor.

Por outro lado, no acórdão da referida turma recursal do Estado do Rio Grande do Sul, o entendimento foi pela não aplicação do direito de arrependimento, sob o fundamento da compra ter sido realizada na loja do fornecedor, mesmo sem o consumidor ter o contato com o produto contratado. Revela-se, portanto, e ser perceptível que nem sempre a aplicação do direito de arrependimento nas aquisições presenciais ainda que o consumidor não tenha tido acesso ao produto será aplicado, por ainda não estar regulada legalmente.

Contudo, o PL n. 3.514/2015, que tramita sob o regime de prioridade na Câmara dos Deputados, traz alterações significativas ao artigo 49 da Lei n. 8.078/90 e prevê mudanças no $\mathrm{CDC}$ para aplicar esse direito também às compras realizadas presencialmente, nas quais o fornecedor não tenha oportunizado ao consumidor o contato com o produto adquirido.

Entretanto, até que ocorra a aprovação do PL n. 3.514/2015, é relevante que os princípios do direito do consumidor orientem a solução dos conflitos nos casos de aquisições no estabelecimento sem contato físico com o produto, especialmente, por meio do princípio da boa-fé, que impõe lealdade e probidade as partes envolvidas na relação de consumo, possibilitando assim que o consumidor exerça o direito de arrependimento e tenha assegurado sua proteção.

\section{REFERÊNCIAS}

AGUIAR JÚNIOR, Ruy Rosado de. O novo código civil e o código de defesa do consumidor: pontos de convergência. Rio de Janeiro: Emerj. V.6, n.24, 2003. Disponível em:

$<$ http://www.emerj.tjrj.jus.br/revistaemerj_online/edicoes/revista24/revista24_15.pdf $>$. Acesso em: 20 abr. 2020.

BOLINA, Beatryz Diniz. O comércio eletrônico e as garantias protetivas do consumidor. Trabalho de Conclusão de curso (Bacharelado em Direito) Unievangélica, Anápolis, 2018. Disponível em:

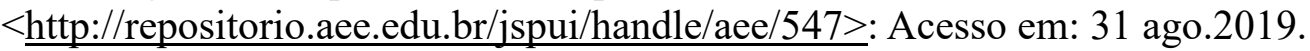


CAVALIERI FILHO, Sergio. Programa de direito do consumidor. 3. ed. São Paulo: Atlas, 2011.

GOMIDE, Alexandre Junqueira. Direito de Arrependimento nos Contratos de Consumo. São Paulo: ed. Almedina, 2014.

INFANTE, Graciela Damiani Corbalan. Reflexões abrangendo o direito de arrependimento na defesa do consumidor. Trabalho de Monografia de conclusão de curso ( Bacharel em Direito) - Faculdade Integradas "Antonio Eufrásio de Toledo". Presidente Prudente, 2008.2 Disponível em: $<$ http://www.unitoledo.br/repositorio/handle/7574/1065>. Acesso em: 21 fev. 2020.

LIMA, Rogério Montai de. Relações contratuais na Internet e Proteção Jurídica do Consumidor. São Paulo: Nelpa, 2008.

MARQUES, Cláudia Lima. Confiança no comércio eletrônico e a proteção do consumidor. São Paulo: Revista dos Tribunais, 2004.

MENDONÇA, Camila Dabrowski de Araújo. Princípio da vulnerabilidade e direito de arrependimento nas contratações em estabelecimento comercial sem que o consumidor tenha acesso ao produto ou serviço. Trabalho de Monografia de Conclusão de Curso de graduação em Direito - Unisul - Universidade do Sul de Santa Catarina. Palhoça, 2019. Disponível em: <http://www.riuni.unisul.br/handle/12345/7493>. Acesso em: 22 fev. 2020.

MOREIRA, Tatiana Artioli. O comércio eletrônico e a proteção do consumidor no Direito Brasileiro. 2016. 215 p. Dissertação em Direito (Mestrado). Pontifícia Universidade Católica de São Paulo - PUC. São Paulo, 2016. Disponível em: < https://bit.ly/3DQpS8S>. Acesso em: 20 fev. 2020.

NUNES, Rizzatto. Curso de direito do consumidor. 12. ed. SãoPaulo: ed. Saraiva, 2018.

RIO GRANDE DO SUL. Tribunal de Justiça. Recurso Inominado n. 71006032197; Relator: Dr. Luis Francisco Franco. Comarca de Porto Alegre/RS. Data do julgamento: 28 de Julho de 2016. Disponível em: <https://www.tjrs.jus.br/novo/buscassolr/?aba=jurisprudencia\&q=\&conteudo_busca=ementa_completa $>$. Acesso em: $20 \mathrm{abr}$. 2020.

SAIKI, Wilson. Análise técnica do defeito e do vício do produto à luz do Código de Defesa do Consumidor. Revista destaque jurídico (online) Ulbra. Gravataí.V.1, n. 1/2. p.116 -137.2012.Disponível em:

$<$ https://gravatai.ulbra.tche.br/jornal/index.php/destaquejuridico/issue/view/4 $>$ Acesso em: 21 fev. 2020.

SÃO PAULO. Tribunal de Justiça. Apelação Cível n. 0004688-42.2010.8.26.0038. Relator: Des. Francisco Casconi. São Paulo, 23 de julho de 2013a. Disponível em: $<$ https://esaj.tjsp.jus.br/cjsg/getArquivo.do?cdAcordao $=6876883 \&$ cdForo $=0>$ Acesso em: 20 abr. 2020. 
. Apelação Cível n. 0017312-72-2013.8.26.0506. Relator Des (a) Jonize Jonize Sacchi de Oliveira. São Paulo. 16 de fevereiro de 2017. Disponível em:

$<\underline{\text { https://esaj.tjsp.jus.br/cjsg/resultadoSimples.do? conversationId }=\& \text { nuProcOrigem }=001}$ 73127220138260506\&nuRegistro $=20170000113631>$. Acesso em: 28 abr. 2020.

Agravo de Instrumento n. 0000882-84.2008.8.26.0000. Relator: Des. Felipe Ferreira. São Paulo, 28 de janeiro de 2008. Disponível em:

$<$ https://esaj.tjsp.jus.br/cjsg/getArquivo.d]o?cdAcordao $=2457211 \&$ cdForo $=0>$. Acesso em: 22 abr. 2020.

SILVA, João Calvão da. A responsabilidade civil do produtor. Coimbra, ed. Almedina, 1990.

SILVA NETO, Orlando Celso da. Comentários ao Código de Defesa do Consumidor. Rio de Janeiro: ed. Forense, 2013.

TARTUCE, Flávio; NEVES, Daniel Amorim Assumpção. Manual de direito do consumidor: direito material e processual. 7. ed. rev. atual. e ampl. Rio de Janeiro: Forense; São Paulo: Método, 2018. 